\title{
Electrospinning of cyclodextrin/linalool-inclusion complex nanofibers: Fast-dissolving nanofibrous web with prolonged release and antibacterial activity
}

\author{
Zeynep Aytac ${ }^{a}$, Zehra Irem Yildiz ${ }^{a}$, Fatma Kayaci-Senirmak ${ }^{a}$, Turgay Tekinay ${ }^{\text {b,c }}$, Tamer Uyar ${ }^{\text {a,* }}$ \\ ${ }^{a}$ Institute of Materials Science E Nanotechnology, UNAM-National Nanotechnology Research Center, Bilkent University, Ankara 06800, Turkey \\ ${ }^{\mathrm{b}}$ Life Sciences Application and Research Center, Gazi University, Ankara 06830, Turkey \\ ${ }^{c}$ Department of Medical Biology and Genetics, Faculty of Medicine, Gazi University, Ankara 06560, Turkey
}

\section{A R T I C L E I N F O}

\section{Article history:}

Received 5 October 2016

Received in revised form 9 March 2017

Accepted 22 March 2017

Available online 23 March 2017

\section{Keywords:}

Antibacterial activity

Cyclodextrin

Electrospinning

Nanofibers

Inclusion complex

Linalool

Nanofiber

Release

\begin{abstract}
A B S T R A C T
The volatility and limited water solubility of linalool is a critical issue to be solved. Here, we demonstrated the electrospinning of polymer-free nanofibrous webs of cyclodextrin/linalool-inclusion complex ( $\mathrm{CD} /$ linalool-IC-NFs). Three types of modified cyclodextrin (HP $\beta C D, M \beta C D$, and $\mathrm{HP} \gamma \mathrm{CD}$ ) were used to electrospin $\mathrm{CD}$ /linalool-IC-NFs. Free-standing $\mathrm{CD}$ /linalool-IC-NFs facilitate maximum loading of linalool up to $12 \%(\mathrm{w} / \mathrm{w})$. A significant amount of linalool (45-89\%) was preserved in $\mathrm{CD} /$ linalool-IC-NFs, due to enhancement in the thermal stability of linalool by cyclodextrin inclusion complexation. Remarkably, $\mathrm{CD} /$ linalool-IC-NFs have shown fast-dissolving characteristics in which these nanofibrous webs dissolved in water within two seconds. Furthermore, linalool release from $\mathrm{CD}$ /linalool-IC-NFs inhibited growth of model Gram-negative (E. coli) and Gram-positive (S. aureus) bacteria to a great extent. Briefly, characteristics of liquid linalool have been preserved in a solid nanofiber form and designed CD/linalool-IC-NFs confer high loading capacity, enhanced shelf life and strong antibacterial activity of linalool.
\end{abstract}

(c) 2017 Elsevier Ltd. All rights reserved.

\section{Introduction}

Cyclodextrins (CDs) (Fig. 1a) are cyclic oligosaccharides produced from the enzymatic degradation of starch. Chemicallymodified CDs (hydroxypropyl and methylated CDs) have been synthesized to enhance the solubility, complexation ability and toxicological profiles in comparison to parent CDs. The distinct character of CDs is related to their relatively hydrophobic cavity allowing the residence of various types of molecules of appropriate polarity and dimensions. Thus, CDs are capable of making hostguest inclusion complexes (ICs) by reducing the volatility; enhancing the stability, solubility and bioavailability. Another significant property of CDs is their non-toxicity that allows them to be used in pharmaceutical, cosmetic and food industries (Del Valle, 2004; Hedges, 1998; Szejtli, 1998).

Electrospinning has gained interest as a versatile technique to produce functional nanofibers and nanofibrous materials for potential applications in filtration, biotechnology, sensors and energy, etc. (Barhate \& Ramakrishna, 2007; Sill \& von Recum,

\footnotetext{
* Corresponding author.

E-mail address: tamer@unam.bilkent.edu.tr (T. Uyar).
}

2008; Uyar \& Kny, 2017; Wendorff, Agarwal, \& Greiner, 2012). Moreover, recent reports have shown that electrospinning and electrospun nanofibrous materials could be applicable in food, food packaging and the agricultural industries (Bhushani \& Anandharamakrishnan, 2014; Kriegel, Arrechi, Kit, McClements, \& Weiss, 2008; Mendes, Stephansen, \& Chronakis, 2016; Noruzi, 2016). Due to the nanoscale diameter range of electrospun fibers, electrospun nanofibrous webs have high surface area and highly porous structure, in addition, design flexibility and easy encapsulation of active agents is a great advantage of electrospun nanofibers. Although melt electrospinning is possible (Góra, Sahay, Thavasi, \& Ramakrishna, 2011), solution electrospinning is mostly employed for producing nanofibers in which polymers are being dissolved and electrospun from their concentrated solutions (Uyar \& Kny, 2017; Wendorff et al., 2012). Since most of the polymers are synthetic-based and the majority of the polymers are dissolved in organic solvents having environmental hazards, the electrospinning process which involves the use of organic solvents somewhat limits the application of such electrospun materials in healthcare, pharmaceuticals, food and food packaging. Therefore, water soluble and bio-renewable materials such as starch-based oligosaccharides (i.e. cyclodextrins) could be alternative materials to 
a.

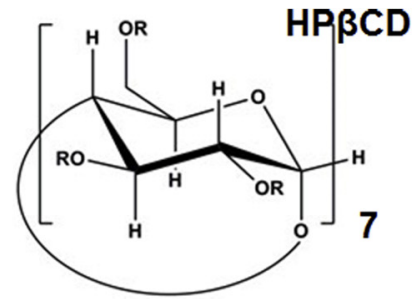

$\mathrm{R}=\mathrm{CH}_{2} \mathrm{CH}(\mathrm{OH}) \mathrm{CH}_{3}$ or $\mathrm{H}$

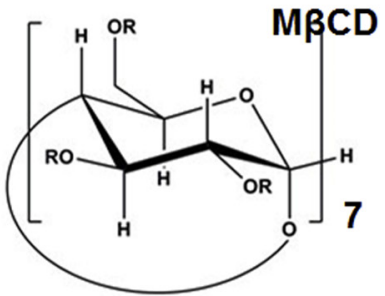

$\mathrm{R}=\mathrm{CH}_{3}$ or $\mathrm{H}$

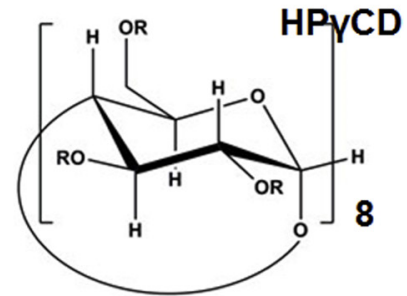

$\mathrm{R}=\mathrm{CH}_{2} \mathrm{CH}(\mathrm{OH}) \mathrm{CH}_{3}$ or $\mathrm{H}$

b.<smiles>C=CC(C)(O)CCC=C(C)C</smiles>

linalool

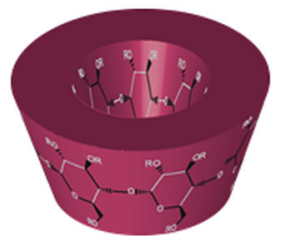

cyclodextrin (CD)

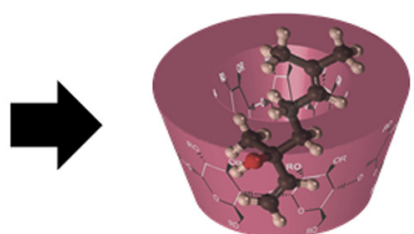

CD/linalool-IC

C.

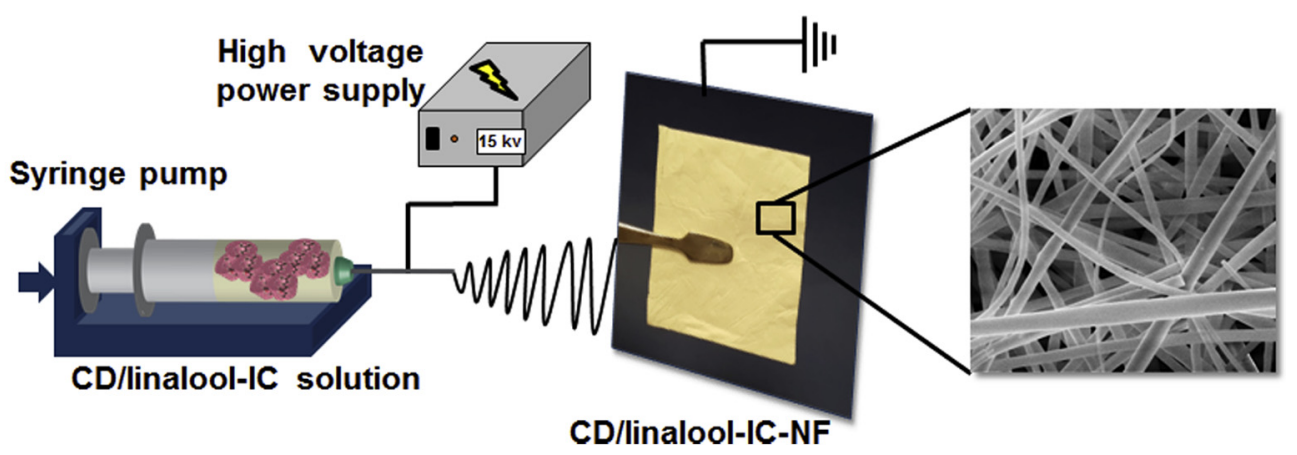

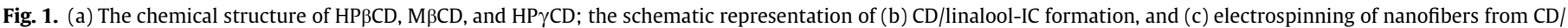
linalool-IC aqueous solution.

produce bio-based nanofibrous materials by using the electrospinning technique.

In our previous studies, we have shown that it is also possible to achieve electrospinning of nanofibers from CDs without using a polymeric matrix, thanks to the formation of sufficient aggregation in their highly concentrated solutions (Celebioglu \& Uyar, 2010, 2012). In addition, CDs have distinct advantages over many molecules, since they can form host-guest ICs with a variety of compounds. The production of CD-IC incorporated polymeric nanofibers has been previously reported by our group (Aytac, Dogan, Tekinay, \& Uyar, 2014; Aytac, Kusku, Durgun, \& Uyar, 2016a,b; Aytac, Sen, Durgun, \& Uyar, 2015; Aytac \& Uyar, 2016; Kayaci, Sen, Durgun, \& Uyar, 2014; Kayaci \& Uyar, 2012; Uyar, Hacaloglu, \& Besenbacher, 2009; Uyar, Nur, Hacaloglu, \& Besenbacher, 2009, 2011). However, organic solvents have been used in most of these studies in order to dissolve the polymeric matrix for the preparation of solution for electrospinning. Furthermore, the weight percent loading of guest molecule was limited (mostly up to $5 \%(\mathrm{w} / \mathrm{w})$, which corresponds to $50 \%(\mathrm{w} / \mathrm{w})$ of CD with respect to fiber matrix when 1:1 molar ratio of host molecule to guest $\mathrm{CD}$ was used) in the case of $\mathrm{CD}$-IC incorporated polymeric nanofibers, since the electrospinnability of the system was disturbed when higher amount of CD-IC was incorporated. On the other hand, polymer-free CD-IC nanofibers produced in aqueous solution might be loaded with $10-15 \%(w / w$, with respect to fiber matrix) guest molecules. Polymer-free $\mathrm{CD}$-IC nanofibers have been produced from IC of a non-volatile compound triclosan (Celebioglu, Umu, Tekinay, \& Uyar, 2014; Celebioglu \& Uyar, 2011) and volatile compounds such as geraniol (Aytac, Yildiz, Kayaci-Senirmak, San Keskin, Tekinay et al., 2016), limonene (Aytac, Yildiz, KayaciSenirmak, San Keskin, Kusku et al., 2016), and vanillin (Celebioglu, Kayaci-Senirmak, Ipek, Durgun, \& Uyar, 2016).

Linalool (3,7-dimethyl-1,6-octadien-3-ol) is an acyclic monoterpene tertiary alcohol known for its volatile and hydrophobic nature. It is found in shampoos, shower gels, soaps, body lotions, hairsprays, creams, antiperspirants, as well as in household cleaners, detergents and food products. Linalool has antimicrobial, anti-inflammatory, local anaesthetic, analgesic and antitumoral activities (Aprotosoaie, Hăncianu, Costache, \& Miron, 2014). Linalool can form ICs with many CD types $\alpha-C D, \beta-C D, \gamma-C D, H P \beta C D$, and $\mathrm{HP} \gamma \mathrm{CD}$ (Ciobanu et al., 2012). There are studies dealing with the IC formation with CDs, aiming to overcome the limitations of linalool, including low solubility and stability (Bonetti, de Moraes, Zanin, \& de Cássia Bergamasco, 2016; Numanoglu et al., 2007). Fast-dissolving drugs and food supplements became important since they can rapidly disintegrate in the oral cavity without the need of water; in addition they show enhanced solubility and bioavailability. For example, oral fast-dissolving membranes are included in fast-dissolving drug delivery systems and they can be easily dissolved in mouth to deliver the drugs (Yu et al., 2009). Electrospinning is a technique that is capable of incorporating active agents (such as drugs and food additives, etc.) into nanofi- 
bers and nanofibrous webs. The release and dissolution rate of such active agents are enhanced owing to high specific surface area and highly porous network.

Here, modified CDs (HP $\beta C D, M \beta C D$, and $H P \gamma C D$ ) which are pharmaceutical grade and commercially available were used for inclusion complexation with linalool (Fig. 1b). Modified CDs are chosen because of their much higher water solubility when compared to native CDs, which makes it possible to perform electrospinning of nanofibers from their highly concentrated aqueous CD-IC solutions. In addition, the difference in the substitution group and the cavity size enables the comparison of complexation and release behavior of the $\mathrm{CD}$-IC nanofibers composed of each $\mathrm{CD}$ type. Then, CD/linalool-IC nanofibrous webs (CD/linalool-IC-NFs) were produced via electrospinning (Fig. 1c). In addition to characterization, short-term temperature-dependent release, long-term release, release at $60 \pm 2 \% \mathrm{RH}$ from $\mathrm{CD} /$ linalool-IC-NFs and antibacterial activity of $\mathrm{CD} /$ linalool-IC-NFs were investigated.

\section{Experimental}

\subsection{Materials}

Linalool (97\%, Sigma Aldrich) and deuterated dimethylsulfoxide (DMSO- $d_{6}$, deuteration degree min $99.8 \%$ for NMR spectroscopy, Merck) were purchased. The modified cyclodextrins; hydroxypropyl-beta-cyclodextrin (HP $\beta C D$, CAVASOL $^{\circledR}$ W7 HP PHARMA), methylated-beta-cyclodextrin (M $\beta C D, \quad$ CAVASOL $^{\circledR}$ W7M PHARMA) and hydroxypropyl-gamma-cyclodextrin (HP $\gamma \mathrm{CD}$, CAVASOL ${ }^{\circledR}$ W8 HP PHARMA) were kindly donated by Wacker Chemie (Germany) and used as-received. The solutions were prepared from water purified in a Millipore Milli-Q ultrapure water system.

\subsection{Preparation of inclusion complexes}

Cyclodextrins (CDs) $(200 \%, \mathrm{w} / \mathrm{v})$ were dissolved in water and then linalool was added into each solution to obtain $\mathrm{CD} /$ linaloolinclusion complex (CD/linalool-IC) solutions. The molar ratio was 1:1 between CDs (HP $\beta C D, M \beta C D$, and $H P \gamma C D$ ) and linalool. $\mathrm{HP} \beta \mathrm{CD}$ /linalool-IC-NF, M $\beta \mathrm{CD}$ /linalool-IC-NF, and $\mathrm{HP} \gamma \mathrm{CD} /$ linaloolIC-NF were produced via electrospinning after stirring the solutions for $12 \mathrm{~h}$ at $25^{\circ} \mathrm{C}$. The properties of $\mathrm{CD} /$ linalool-IC solutions (composition, viscosity, and conductivity) and morphological characteristics of $\mathrm{CD} /$ linalool-IC-NFs including average fiber diameter (AFD) values are given in Supporting Table S1. HP $\beta C D-N F$, M $\beta C D-$ $\mathrm{NF}$, and HP $\gamma \mathrm{CD}-\mathrm{NF}$ were also prepared for reference (Celebioglu \& Uyar, 2010, 2012).

\subsection{Electrospinning}

The solutions of $\mathrm{CD} /$ linalool-ICs were put in a plastic syringe having metallic needle of $0.4 \mathrm{~mm}$ inner diameter and the syringe was positioned horizontally on a syringe pump (KDS-101; KD Scientific, Holliston, MA). A grounded metal collector covered by aluminum foil was placed $10 \mathrm{~cm}$ away from the needle tip. $\mathrm{CD} /$ linalool-IC solutions were sent towards the collector via syringe pump at a constant rate $(0.5 \mathrm{~mL} / \mathrm{h})$. High voltage $(15-20 \mathrm{kV})$ was applied from a high voltage power supply (AU Series; Matsusada Precision Inc., Kyoto, Japan). Lastly, CD/linalool-IC-NFs were produced in an enclosed Plexiglas box at $25^{\circ} \mathrm{C}$ and $18 \% \mathrm{RH}$.

\subsection{Characterizations and measurements}

\subsubsection{Phase-solubility study}

Phase-solubility measurements for $\mathrm{CD} /$ linalool-IC systems were carried out in aqueous solution (Higuchi \& Connors, 1965). An excess amount of linalool was added to $C D(H P \beta C D, M \beta C D$, and $\mathrm{HP} \gamma(\mathrm{CD})$ solutions and the suspensions were shaken at RT for 48 hours. After equilibrium was achieved, the suspensions were filtered and UV spectroscopy measurements were done at $283 \mathrm{~nm}$ (Cary 100, Varian). The experiments were carried out in triplicate and each data point is the average of the three determinations.

The stability constant $\left(K_{\mathrm{C}}\right)$ was calculated based on the phase solubility diagram according to the following equation:

$K_{C}=$ slope $/ S_{0}(1-$ slope $)$

where $S_{0}$ is the intrinsic solubility of linalool in the absence of CDs.

\subsubsection{Viscosity and conductivity measurement}

An Anton Paar Physica MCR 301 rheometer (Anton Paar, Graz, Austria) equipped with a cone/plate accessory (spindle type $\mathrm{CP}$ 40-2) at a constant shear rate of $100 \mathrm{~s}^{-1}$ was used to measure the viscosity of $\mathrm{HP} \beta \mathrm{CD} /$ linalool-IC, $\mathrm{M} \beta \mathrm{CD} /$ linalool-IC, and $\mathrm{HP} \gamma \mathrm{CD} /$ linalool-IC solutions at RT. The solution conductivity of $\mathrm{CD} /$ linalool-IC systems was determined via Inolab $^{\circledR} 720 \mathrm{pH} /$ Cond (WTW GmbH, Weilheim, Germany) at RT.

\subsubsection{Morphology analysis of nanofibers}

The morphological characterization of electrospun $\mathrm{HP} \beta \mathrm{CD} /$ linalool-IC-NF, M $\beta C D /$ linalool-IC-NF, and $\mathrm{HP} \gamma \mathrm{CD} /$ linalool-IC-NF was performed by using scanning electron microscopy (SEM; Quanta 200 FEG; FEI, Hillsboro, OR). The nanofibrous web samples were coated with $5 \mathrm{~nm} \mathrm{Au} / \mathrm{Pd}$ (PECS-682) to minimize the charging before taking SEM images. AFD of the nanofibers were calculated on SEM images $(n \geq 100)$. The results were reported as mean \pm standard deviation.

\subsubsection{Solubility of nanofibers}

In order to show the solubility time of nanofibers, $5 \mathrm{~mL}$ of water were added to linalool in a vial and $\mathrm{HP} \beta \mathrm{CD} /$ linalool-IC-NF, $\mathrm{M} \beta \mathrm{CD} /$ linalool-IC-NF, and HP $\gamma \mathrm{CD} /$ linalool-IC-NF in Petri dishes. Then, video was recorded for linalool and nanofibers separately.

\subsubsection{Molar ratio of nanofibers}

$\mathrm{HP} \beta \mathrm{CD} /$ linalool-IC-NF, $\mathrm{M} \beta \mathrm{CD} /$ linalool-IC-NF, and $\mathrm{HP} \gamma \mathrm{CD} /$ linalool-IC-NF (all $10 \mathrm{mg}$ ) were dissolved in $500 \mu \mathrm{L}$ of d6-DMSO to calculate the molar ratio of each $\mathrm{CD}$ and linalool. Then, proton nuclear magnetic resonance $\left({ }^{1} \mathrm{H}\right.$ NMR) spectra were recorded for each solution using a Bruker DPX-400. The integration of the chemical shifts $(\delta)$ was calculated via Mestrenova software. In addition, ${ }^{1} \mathrm{H}$ NMR spectra were recorded for nanofibers $(10 \mathrm{mg})$ after incubating them at RT for 25 days.

\subsubsection{Thermal analyses of nanofibers}

The thermal properties of linalool, HP $\beta C D-N F, M \beta C D-N F$, HP $\gamma C D-N F, \quad H P \beta C D /$ linalool-IC-NF, $\quad M \beta C D /$ linalool-IC-NF, and $\mathrm{HP} \gamma \mathrm{CD} /$ linalool-IC-NF were investigated via thermogravimetric analysis (TGA; TA Q500; TA Instruments, New Castle, DE) and differential scanning calorimetry (DSC, TA Q2000; TA Instruments). TGA measurements were performed under nitrogen atmosphere and the samples were heated from $25^{\circ} \mathrm{C}$ to $450{ }^{\circ} \mathrm{C}$ at the rate of $20^{\circ} \mathrm{C} / \mathrm{min}$; whereas DSC analyses were carried out in a nitrogen inert atmosphere by heating the samples from $25^{\circ} \mathrm{C}$ to $190{ }^{\circ} \mathrm{C}$ at a rate of $20^{\circ} \mathrm{C} / \mathrm{min}$.

\subsubsection{Structural characterisation}

The crystalline structure of $\mathrm{HP} \beta \mathrm{CD} /$ linalool-IC-NF, $\mathrm{M} \beta \mathrm{CD} /$ linalool-IC-NF, and HP $\gamma \mathrm{CD}$ /linalool-IC-NF was examined with Xray diffraction (XRD; PANalytical X'Pert powder diffractometer; PANalytical B.V., Almelo, The Netherlands). XRD was not carried out for linalool because of its liquid nature at RT. For comparison, XRD patterns of HP $\beta C D-N F, M \beta C D-N F, H P \gamma C D-N F$ were recorded 
as well. XRD data were obtained applying $\mathrm{Cu} \mathrm{K} \alpha$ radiation in powder diffraction configuration in the $2 \theta$ range of $5-30^{\circ}$.

\subsubsection{Release study}

$\mathrm{HP} \beta \mathrm{CD} /$ linalool-IC-NF, $\mathrm{M} \beta \mathrm{CD} /$ linalool-IC-NF, and $\mathrm{HP} \gamma \mathrm{CD} /$ linalool-IC-NF $(10 \mathrm{mg})$ were put into headspace glass vials $(20 \mathrm{~mL})$. The amount of linalool released from nanofibers at $37^{\circ} \mathrm{C}, 50{ }^{\circ} \mathrm{C}$, and $75^{\circ} \mathrm{C}$ and $20 \% \mathrm{RH}$ was measured at predetermined time intervals for $3 \mathrm{~h}$ via headspace gas chromatography-mass spectrometry (HS GC-MS; Agilent Technologies 7890A gas chromatograph equipped with 5975C mass spectrometer; Agilent, Santa Clara, CA) using an HP-5MS (30 $\mathrm{m} \times 0.25 \mathrm{~mm}$ i.d., $0.25 \mathrm{~m}$ film thickness; Agilent) capillary column. A $250-\mu \mathrm{L}$ aliquot of vapor was injected using a headspace injector (MSH 02-00B, volume: $2.5 \mathrm{~mL}$, scale: $60 \mathrm{~mm})$. The $\mathrm{GC}$ oven was held at $40{ }^{\circ} \mathrm{C}(3 \mathrm{~min})$ and then the temperature was increased at a rate of $10^{\circ} \mathrm{C} / \mathrm{min}$ to $175^{\circ} \mathrm{C}$ ( $\left.3 \mathrm{~min}\right)$. Selected ion monitoring mode of the instrument and NIST MS Search 2.0 mass spectral library were employed to determine the peaks of linalool. The release experiments were carried out in triplicate from three different samples of each $\mathrm{CD} /$ linalool-IC-NFs. Mean and standard deviation were calculated for each system.

HP $\beta C D /$ linalool-IC-NF, M $\beta C D /$ linalool-IC-NF, and $\mathrm{HP} \gamma \mathrm{CD} /$ linalool-IC-NF were kept for 50 days in the open air in the laboratory
(RT, 18\% RH). TGA was carried out at the end of 25 and 50 days to determine the amount of linalool remaining in the nanofibers.

Finally, $\quad H P \beta C D /$ linalool-IC-NF, $\quad \mathrm{M} \beta C D /$ linalool-IC-NF, and $\mathrm{HP} \gamma \mathrm{CD} /$ linalool-IC-NF were kept for $6 \mathrm{~h}$ and $24 \mathrm{~h}$ in a cabin at RT and $60 \pm 2 \% \mathrm{RH}$. Then, TGA measurements were done to determine the amount of linalool remaining in the nanofibers.

\subsubsection{Antibacterial activity}

The antibacterial activity of $\mathrm{HP} \beta C \mathrm{CD} /$ linalool-IC-NF, $\mathrm{M} \beta \mathrm{CD} /$ linalool-IC-NF, and HP $\gamma \mathrm{CD} /$ linalool-IC-NF was evaluated using colony counting method against $E$. coli and $S$. aureus. Bacterial cells of E. coli (ATCC 10536) and S. aureus (ATCC 25923) were grown $24 \mathrm{~h}$ on a shaker at $100 \mathrm{rpm}$ and $37^{\circ} \mathrm{C}$. Inoculum was suspended to provide a final density of $1 \times 10^{8}$ colony forming units $(\mathrm{CFU}) / \mathrm{mL}$ in phosphate buffer solution (PBS) according to 0.5 McFarland turbidity standard (approximately $1-2 \times 10^{8} \mathrm{CFU} / \mathrm{mL}$ ). UV sterilized nanofibers ( $40 \mathrm{mg}$ ) were then immersed in bacterial suspension in a $20-\mathrm{mL}$ conical tube, and the media were shaken at $100 \mathrm{rpm}$ at $37^{\circ} \mathrm{C}$ for $24 \mathrm{~h}$. The culture which was diluted in PBS $\left(10^{1}-10^{9}\right)$ was spread on a nutrient agar plate and incubated at $37^{\circ} \mathrm{C}$ overnight and $\mathrm{CFU} / \mathrm{mL}$ were counted. The experiments were performed in triplicate and the results are given as mean \pm standard deviation.

The antibacterial activity of $\mathrm{CD} /$ linalool-IC-NFs was calculated using the following equation:
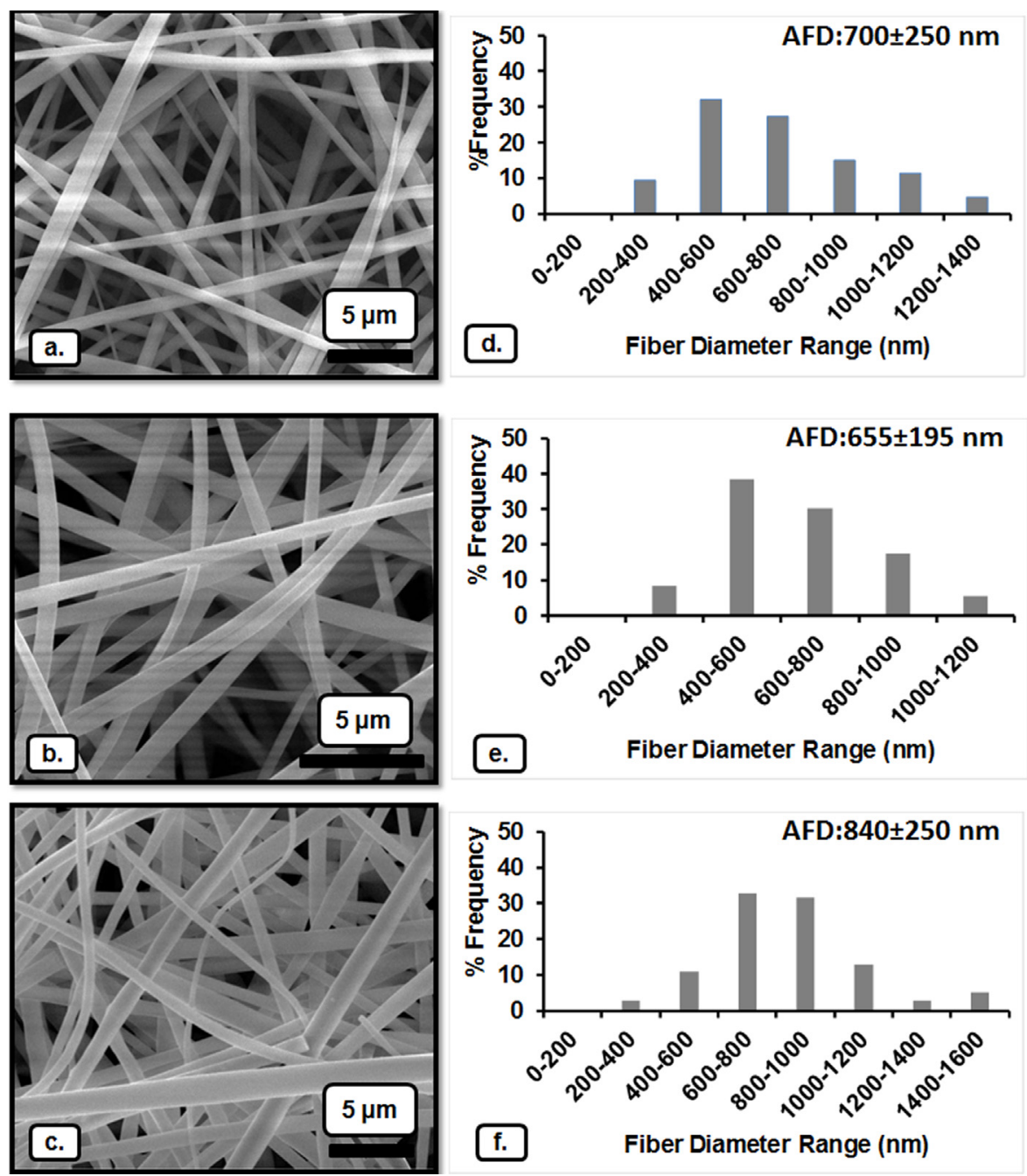
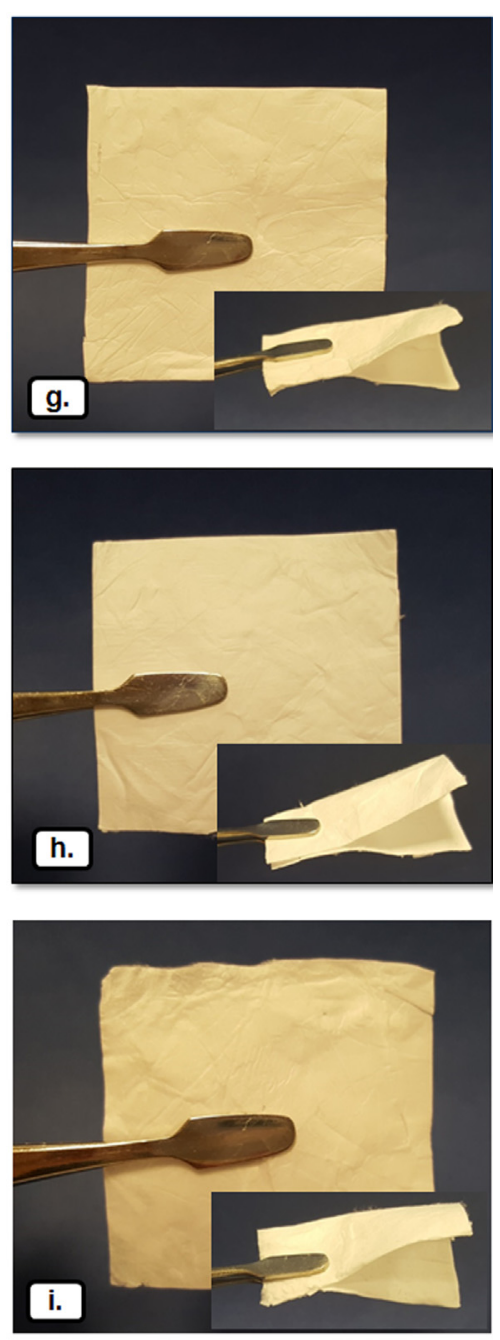

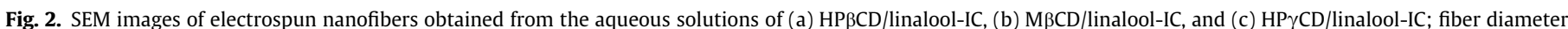

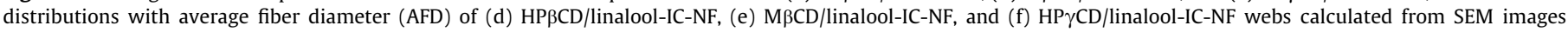
$(n \geq 100)$; the photographs of (g) HPßCD/linalool-IC-NF, (h) M $\beta C D /$ linalool-IC-NF, and (i) HP $\gamma C D /$ linalool-IC-NF webs. 
Antibacterial activity $(\%)=(A-B) / A * 100$

where $A$ is the number of colonies (CFU/mL) in the control group, $B$ is the number of colonies after $\mathrm{CD} /$ linalool-IC-NFs were added.

\section{Results and discussion}

\subsection{Phase solubility studies}

Phase solubility analysis was performed for HP $\beta C D /$ linalool-IC, $\mathrm{M} \beta \mathrm{CD} /$ linalool-IC, and $\mathrm{HP} \gamma \mathrm{CD} /$ linalool-IC systems in aqueous solution to determine the effect of increasing amount of each $C D$ on linalool. The results are given in Fig. S1. The solubility of linalool increased linearly up to $16 \mathrm{mM}$ of $\mathrm{HP} \beta C D$ and $\mathrm{M} \beta C D$; when the concentration of $\mathrm{HP} \beta C D$ and $M \beta C D$ exceeds $16 \mathrm{mM}$ the increase in solubility deviates from linearity. The stability constants $\left(K_{\mathrm{c}}\right)$ of $\mathrm{HP} \beta \mathrm{CD} /$ linalool-IC and $\mathrm{M} \beta \mathrm{CD} /$ linalool-IC systems were calculated as $0.093 \mathrm{M}^{-1}$ and $0.1876 \mathrm{M}^{-1}$ from the initial linear portions of the diagrams according to Eq. (1). The solubility of linalool increased linearly up to $64 \mathrm{mM}$ of $\mathrm{HP} \gamma \mathrm{CD}$. Since the slope of $\mathrm{HP} \gamma \mathrm{CD} /$ linalool-IC system in phase solubility diagram is bigger than 1 , we could not calculate $K_{\mathrm{c}}$ for this CD type. But it is clear that the solubility of linalool was enhanced compared to other CDs and this result might indicate stronger interaction between $\mathrm{HP} \gamma \mathrm{CD}$ and linalool.

\subsection{Morphology analyses of nanofibers}

The concentrations of CDs were determined from our previous study to obtain bead-free nanofibers (Celebioglu \& Uyar, 2012). Here, we used similar concentrations for $\mathrm{CD}$ /linalool-IC solutions, thus solutions were prepared by using three types of modified CDs (HP $\beta C D, M \beta C D$, and $H P \gamma C D$ ) and linalool; then, nanofibers were produced successfully from these solutions. Modified CDs were used, because nanofibers can only be obtained from CD-IC of these CDs not from the native CDs. The particular reasons for using these modified CDs are the difference in the substitution group between $\mathrm{HP} \beta C D$ and $M \beta C D$ and cavity size between $\mathrm{HP} \beta C D$ and $\mathrm{HP} \gamma \mathrm{CD}$, which make possible the comparison of complexation and release behavior of each $C D$.

Scanning electron microscopy (SEM) images and average fiber diameter (AFD) along with fiber distributions of the nanofibers of HP $\beta C D /$ linalool-IC-NF, M $\beta C D /$ linalool-IC-NF, and HP $\gamma C D /$ linaloolIC-NF are given in Fig. 2a-f. Bead-free and uniform nanofibers were successfully produced with the all systems used. The mean fiber diameters of $\mathrm{HP} \beta \mathrm{CD} /$ linalool-IC-NF, $\mathrm{M} \beta \mathrm{CD} /$ linalool-IC-NF, and

a.

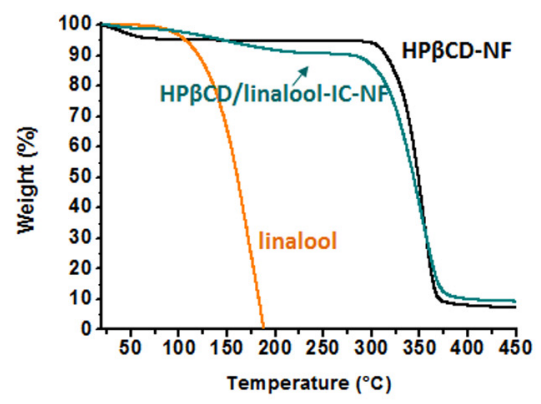

d.

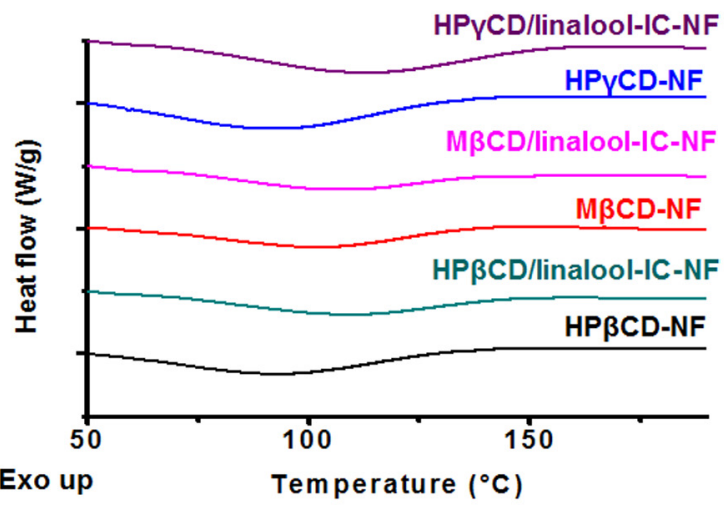

b.

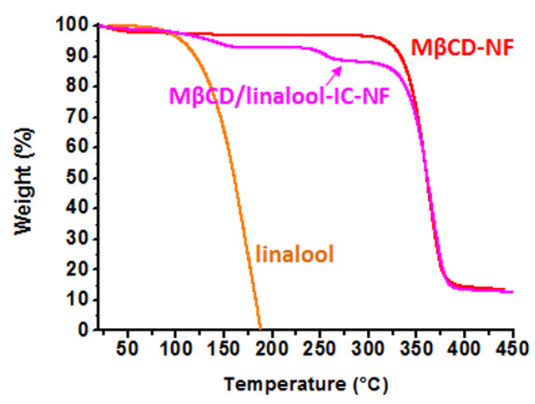

c.

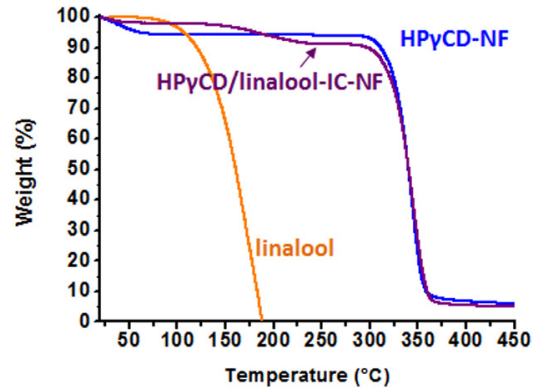

e.

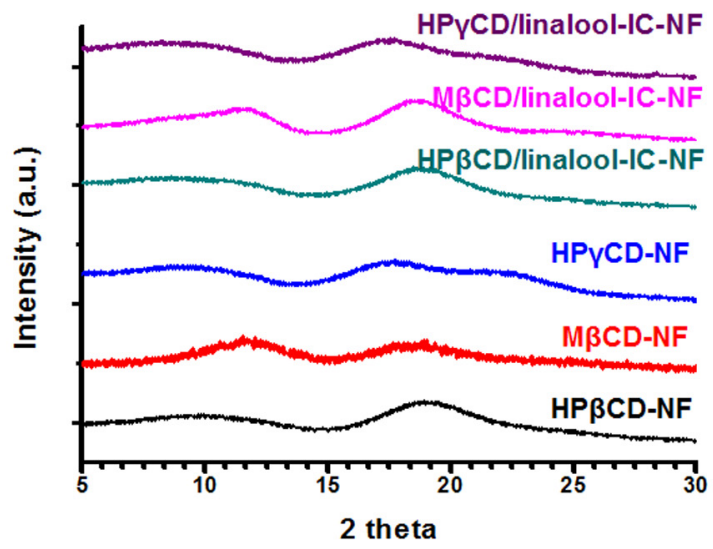

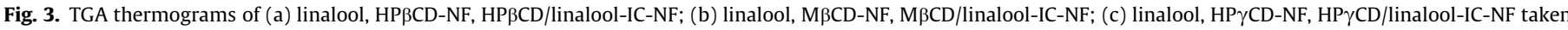

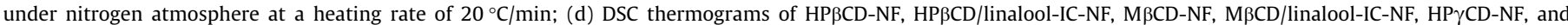

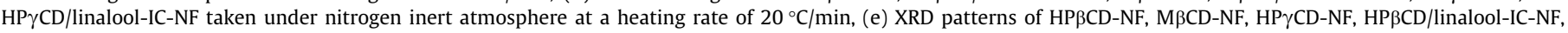
$\mathrm{M} \beta \mathrm{CD} /$ linalool-IC-NF, and HP $\gamma \mathrm{CD} /$ linalool-IC-NF. 
$\mathrm{HP} \gamma \mathrm{CD} /$ linalool-IC-NF were $700 \pm 250 \mathrm{~nm}, 655 \pm 195 \mathrm{~nm}$, and $840 \pm 250 \mathrm{~nm}$, respectively. AFD of M $\beta C D /$ linalool-IC-NF was lower than $\mathrm{HP} \beta C \mathrm{CD} /$ linalool-IC-NF, due to the lower viscosity and higher conductivity of $\mathrm{M} \beta \mathrm{CD} /$ linalool-IC solution compared to $\mathrm{HP} \beta \mathrm{CD} /$ linalool-IC solution (Supporting Table S1). HP $\gamma$ CD/linalool-IC-NF had the highest AFD among all CD/linalool-IC-NFs; the higher viscosity and lower conductivity of $\mathrm{HP} \gamma \mathrm{CD} /$ linalool-IC solution might be the reasons for this situation. The photographs of free-standing, easily-handled CD/linalool-IC-NF webs are shown in Fig. $2 \mathrm{~g}-\mathrm{i}$ ). Although CD/linalool-IC-NF webs are mainly composed of small molecules, they possess mechanical integrity. Moreover, the solubility of linalool, HP $\beta C D /$ linalool-IC-NF, M $\beta C D /$ linalool-IC-NF, and $\mathrm{HP} \gamma \mathrm{CD} /$ linalool-IC-NF in water is shown in Fig. S2 and supporting videos 1 and 2 . As seen from the figure and videos, linalool does not dissolve and an oily material is clearly visible; whereas $\mathrm{CD}$ / linalool-IC-NFs dissolve quickly i.e. within two seconds.

\subsection{The molar ratio of $C D /$ linalool-IC}

The molar ratio of $\mathrm{CDs}(\mathrm{HP} \beta \mathrm{CD}, \mathrm{M} \beta \mathrm{CD}$, and $\mathrm{HP} \gamma \mathrm{CD})$ to linalool in $\mathrm{HP} \beta C D /$ linalool-IC-NF, M $\beta C D /$ linalool-IC-NF, and HP $\gamma C D /$ linaloolIC-NF was calculated from proton nuclear magnetic resonance $\left({ }^{1} \mathrm{H}\right.$ NMR) spectra (Fig. S3a-c). The integration of the characteristic peaks associated with $\mathrm{HP} \beta \mathrm{CD}, \mathrm{M} \beta \mathrm{CD}$, and $\mathrm{HP} \gamma \mathrm{CD}$ (1.00 ppm, 3.5$3.75 \mathrm{ppm}$, and $1.00 \mathrm{ppm}$ ) and linalool (1.5 and $1.6 \mathrm{ppm}$ ) were used to make the calculations. The molar ratios of HP $\beta C D$ :linalool, $\mathrm{M} \beta C \mathrm{CD}$ :linalool, and $\mathrm{HP} \gamma \mathrm{CD}$ :linalool were found to be $1.00: 0.69$, 1.00:0.65, and 1.00:0.45, respectively. Therefore, a remarkable amount of linalool was preserved from evaporation in $\mathrm{HP} \beta \mathrm{CD} /$ linalool-IC-NF (69\%, w/w) and $\mathrm{M} \beta C D /$ linalool-IC-NF $(65 \%, \mathrm{w} / \mathrm{w})$; but $\mathrm{HP} \gamma \mathrm{CD} /$ linalool-IC-NF could preserve only $45 \%(\mathrm{w} / \mathrm{w})$ of linalool during the solution preparation, electrospinning and storage.

\subsection{Thermal analyses of nanofibers}

The thermal stability of $\mathrm{HP} \beta \mathrm{CD} /$ linalool-IC-NF, M $\beta C D /$ linaloolIC-NF, and $\mathrm{HP} \gamma \mathrm{CD}$ /linalool-IC-NF was determined via thermogravimetric analysis (TGA) (Fig. 3a-c). As references, linalool, HP $\beta C D-N F$, $\mathrm{M} \beta \mathrm{CD}-\mathrm{NF}$, and HP $\gamma \mathrm{CD}-\mathrm{NF}$ were also tested. Two steps of weight losses were observed in TGA curves of HP $\beta C D-N F, M \beta C D-N F$, and HP $\gamma$ CD-NF below $100^{\circ} \mathrm{C}$ and above $275^{\circ} \mathrm{C}$, and these weight losses were attributed to the water loss and main thermal degradation of cyclodextrins (CDs), respectively (Celebioglu \& Uyar, 2011). The weight loss below $100^{\circ} \mathrm{C}$ seen in CD/linalool-IC-NFs corresponded to water loss; whereas the weight loss above $275^{\circ} \mathrm{C}, 285^{\circ} \mathrm{C}$, and $275^{\circ} \mathrm{C}$ for $\mathrm{HP} \beta C \mathrm{CD} /$ linalool-IC-NF, $\mathrm{M} \beta \mathrm{CD} /$ linalool-IC-NF, and $\mathrm{HP} \gamma \mathrm{CD} /$ linalool-IC-NF, respectively, were due to the main thermal degradation of CDs. HP $\beta C D /$ linalool-IC-NF and $\mathrm{HP} \gamma \mathrm{CD} /$ linalool-IC$\mathrm{NF}$ exhibited weight losses between $75-235^{\circ} \mathrm{C}$ and $120-260^{\circ} \mathrm{C}$ attributed to linalool. Two weight losses seen in $\mathrm{M} \beta \mathrm{CD} /$ linaloolIC-NF were between $65-170{ }^{\circ} \mathrm{C}$ (5.50\%) and $195-285^{\circ} \mathrm{C}(4.75 \%)$ and belong to evaporation of linalool in two steps. Briefly, it can be deduced that true complexation was successfully formed between the CDs and linalool due to the shift in the thermal evaporation of linalool to higher temperatures. However, the second weight loss exists in $\mathrm{M} \beta \mathrm{CD} /$ linalool-IC-NF has higher thermal stability compared to the first. Thus, two steps of weight loss seen in $\mathrm{M} \beta \mathrm{CD}$ /linalool-IC-NF showed the presence of two types of interaction between $\mathrm{M} \beta \mathrm{CD}$ and linalool; the second one is stronger than the first, due to the shifting of thermal evaporation of linalool to higher temperatures. Moreover, the second weight loss of linalool in $\mathrm{M} \beta \mathrm{CD}$ /linalool-IC-NF has higher thermal stability in comparison to the complexes formed in HP $\beta C D /$ linalool-IC-NF and $\mathrm{HP} \gamma \mathrm{CD} /$ linalool-IC-NF. The amounts of linalool present in $\mathrm{HP} \beta C D /$ linalool-IC-NF, $\mathrm{M} \beta \mathrm{CD} /$ linalool-IC-NF, and $\mathrm{HP} \gamma \mathrm{CD} /$ linalool-IC-NF were $84 \%, 89 \%$ and $77 \%$ of the initial amount of linalool, respectively.
The molar ratios of $\mathrm{HP} \beta C D, M \beta C D$, and $H P \gamma C D$ to linalool were calculated from TGA data as 1.00:0.84, 1.00:0.89 and 1.00:0.77, respectively, based on TGA results. The molar ratios determined from TGA were not identical with the results derived from ${ }^{1} \mathrm{H}$ NMR, but they were comparable, suggesting that a substantial amount of linalool (65-89\%) was protected from evaporation in $\mathrm{HP} \beta C D /$ linalool-IC-NF and M $\beta C D /$ linalool-IC-NF; whereas $\mathrm{HP} \gamma \mathrm{CD}$ / linalool-IC-NF preserved only $45-77 \%$ of linalool. On the other hand, volatile compounds including vanillin, geraniol, and allyl isothiocyanate could not be preserved in electrospun polyvinyl alcohol (PVA) nanofibers in the absence of CD-IC during electrospinning and storage (Aytac et al., 2014; Kayaci \& Uyar, 2012; Kayaci et al., 2014).

Differential scanning calorimetry (DSC) of HP $\beta C D-N F, M \beta C D-$ NF, HP $\gamma$ CD-NF, HP $\beta C D /$ linalool-IC-NF, M $\beta C D /$ linalool-IC-NF, and $\mathrm{HP} \gamma \mathrm{CD} /$ linalool-IC-NF is displayed in Fig. $3 \mathrm{~d}$. Typical broad endothermic peaks of HP $\beta C D-N F, M \beta C D-N F$, and $H P \gamma C D-N F$ were between $25-160^{\circ} \mathrm{C}, 25-155^{\circ} \mathrm{C}$, and $25-155^{\circ} \mathrm{C}$ and the dehydration enthalpies were calculated to be $329 \mathrm{~J} / \mathrm{g}, 99 \mathrm{~J} / \mathrm{g}$, and $255 \mathrm{~J} / \mathrm{g}$ for each system, respectively. It is known that guest molecules compete with water molecules in the cavity of CDs; therefore the enthalpy of dehydration is expected to be lower in the case of complexation when compared to pure $\mathrm{CD}$. Because the water in the cavity of $\mathrm{CDs}$ is replaced by the guest molecule during the complex formation. $\mathrm{HP} \beta \mathrm{CD} /$ linalool-IC-NF, $\mathrm{M} \beta \mathrm{CD} /$ linalool-IC-NF and $\mathrm{HP} \gamma \mathrm{CD} /$ linalool-IC-NF had endothermic peaks between $70-$ $160{ }^{\circ} \mathrm{C}, 75-165^{\circ} \mathrm{C}$, and $65-170{ }^{\circ} \mathrm{C}$ and the enthalpies were calculated as $88 \mathrm{~J} / \mathrm{g}, 49 \mathrm{~J} / \mathrm{g}$, and $125 \mathrm{~J} / \mathrm{g}$, respectively. It is known that
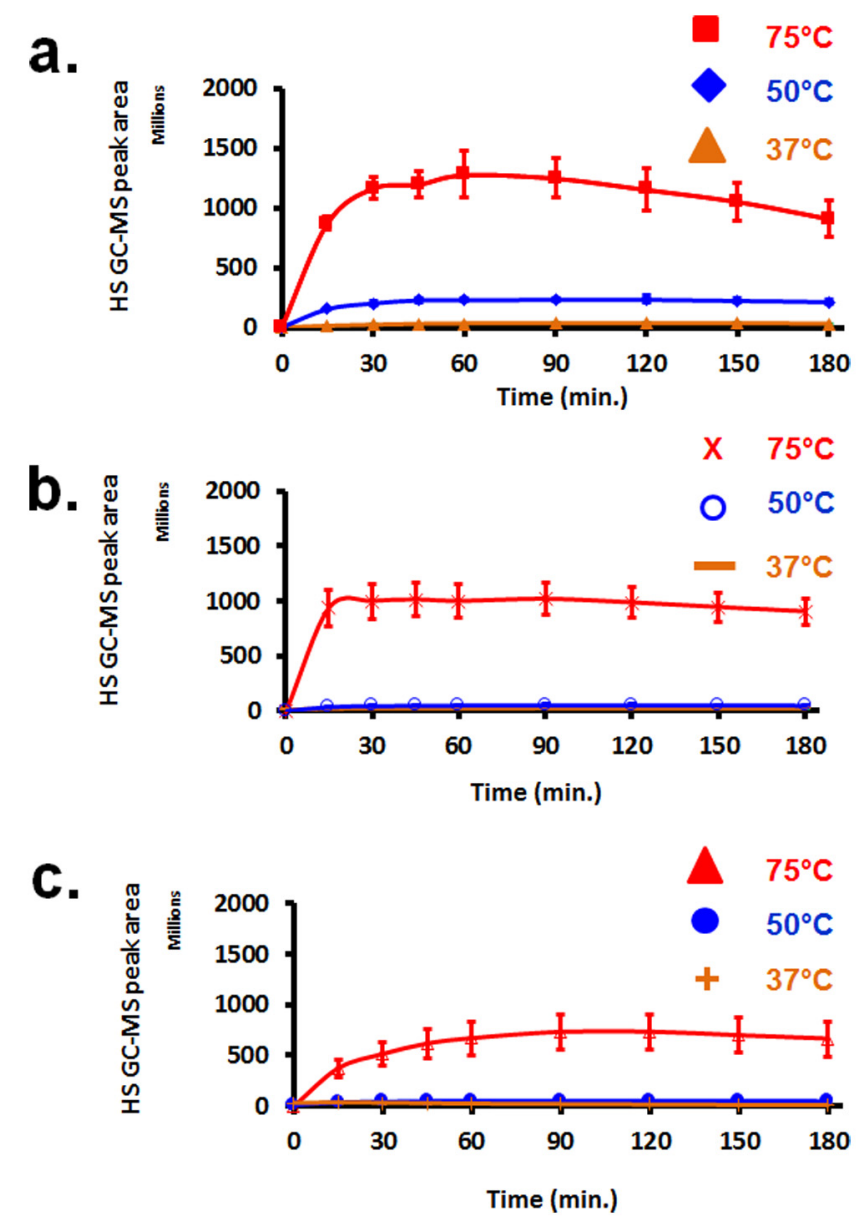

Fig. 4. The cumulative release of linalool from (a) $\mathrm{HP} \beta C D /$ linalool-IC-NF, (b) $\mathrm{M} \beta C \mathrm{CD}$ linalool-IC-NF, and (c) $\mathrm{HP} \gamma \mathrm{CD} /$ linalool-IC-NF at $37^{\circ} \mathrm{C}, 50^{\circ} \mathrm{C}, 75^{\circ} \mathrm{C}$ and $20 \%$ relative humidity $(n=3)$. The error bars in the figure represent the standard deviation (SD). 
the replacement of water molecules in the cavity of CDs with guest molecules leads to reduction in the enthalpy of pristine CDs (Kadam, Bamane, \& Raut, 2014).

\subsection{Structural characterization of nanofibers}

X-ray diffraction (XRD) graphs of HP $\beta C D-N F, M \beta C D-N F, H P \gamma C D-$ NF, $\mathrm{HP} \beta \mathrm{CD} /$ linalool-IC-NF, $\mathrm{M} \beta \mathrm{CD} /$ linalool-IC-NF, and $\mathrm{HP} \gamma \mathrm{CD} /$ linalool-IC-NF are presented in Fig. 3e. Modified CDs have amorphous structure different from their native counterparts because the hydroxyl groups in the native CDs are replaced randomly with functional groups, such as hydroxypropyl or methyl groups, which limit the particular orientation of $\mathrm{CD}$ molecules. It was found that HP $\beta C D /$ linalool-IC-NF, M $\beta C D /$ linalool-IC-NF, and HP $\gamma C D /$ linaloolIC-NF exhibited amorphous structure like HP $\beta C D-N F, M \beta C D-N F$, and HP $\gamma$ CD-NF. The lack of crystal formation of linalool in CD/ linalool-IC-NFs proved complexation was successful.

\subsection{Release study}

The release of linalool from $\mathrm{HP} \beta C \mathrm{CD} /$ linalool-IC-NF, $\mathrm{M} \beta C \mathrm{CD} /$ linalool-IC-NF, and $\mathrm{HP} \gamma \mathrm{CD} /$ linalool-IC-NF at $37^{\circ} \mathrm{C}$, $50^{\circ} \mathrm{C}$, and $75{ }^{\circ} \mathrm{C}$ at $20 \% \mathrm{RH}$ for $3 \mathrm{~h}$ is shown in Fig. $4 \mathrm{a}-\mathrm{c}$. The release of linalool from all CD/linalool-IC-NFs increased with temperature because, as a.

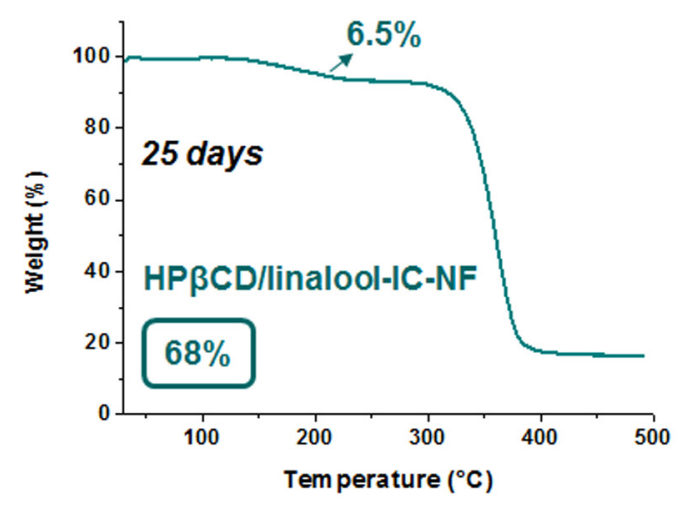

initial amount : $11.5 \%(\mathrm{w} / \mathrm{w})$

b.

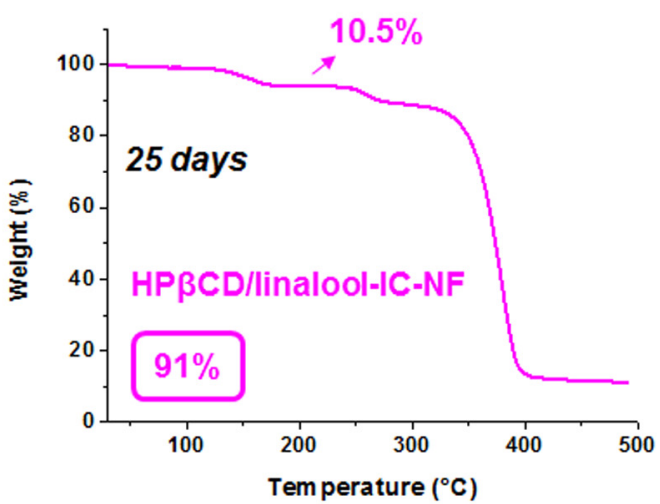

initial amount : $8.7 \%(w / w)$

C.

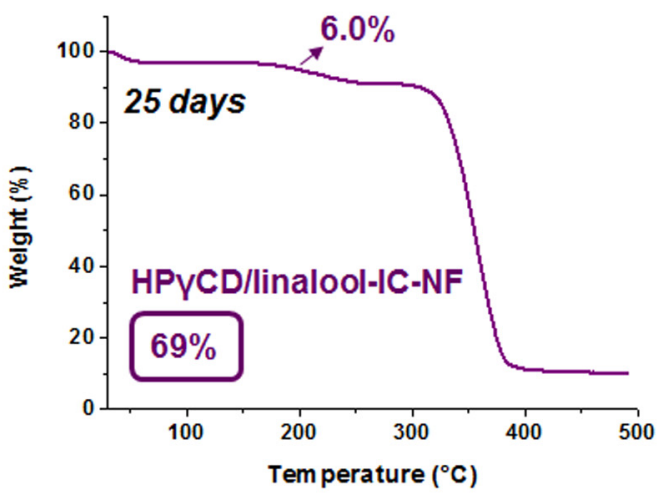

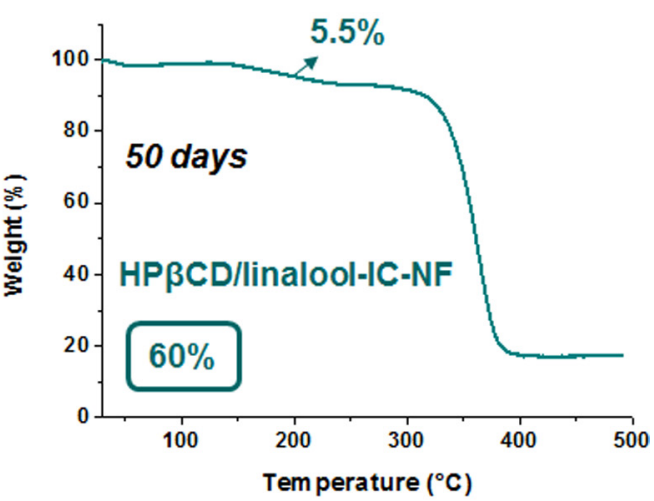
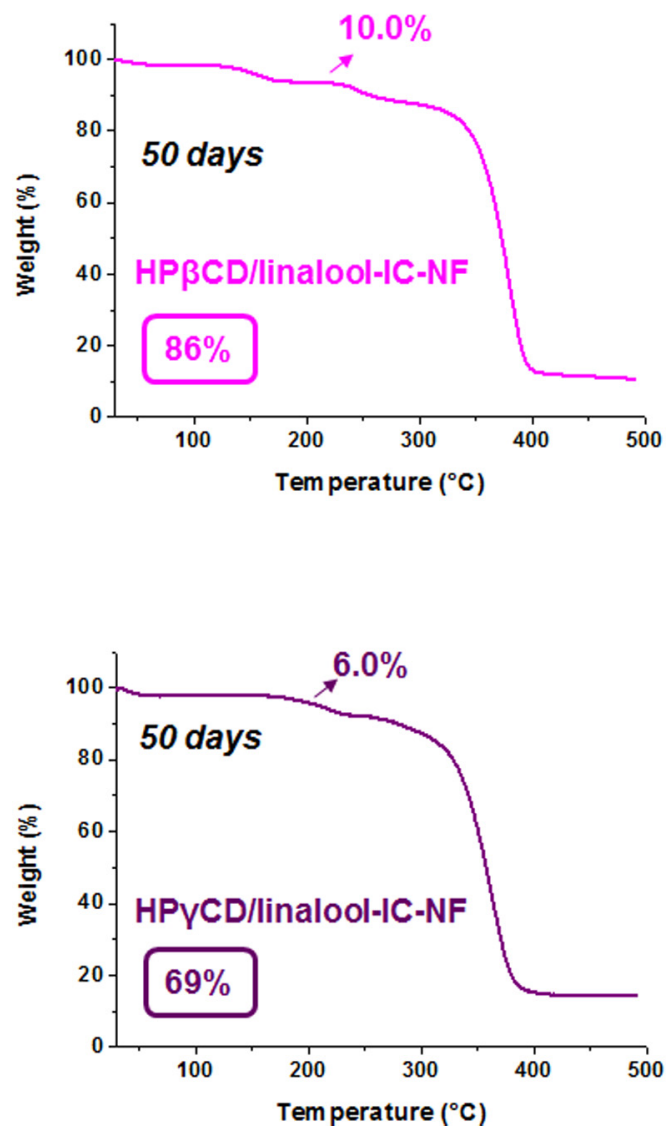

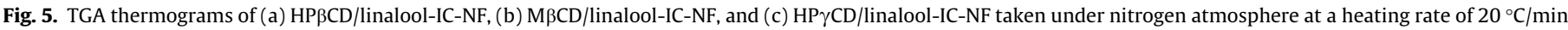
after keeping the nanofibers at RT and $18 \%$ relative humidity for 25 and 50 days. 
the temperature increases, the diffusion coefficient of molecules increases (Hu, Chen, \& Wang, 2012). Secondly, although the preserved amount of linalool is almost the same in $\mathrm{HP} \beta C D /$ linaloolIC-NF and $\mathrm{M} \beta \mathrm{CD} /$ linalool-IC-NF, $\mathrm{HP} \beta \mathrm{CD} /$ linalool-IC-NF released much more linalool in total compared to $\mathrm{M} \beta \mathrm{CD} /$ linalool-IC-NF. This result might be due to the lower thermal stability and stability constant of $\mathrm{HP} \beta C D /$ linalool-IC-NF shown in TGA and phase solubility results (Fig. $3 a-c$ and Fig. S1). Thirdly, since $\mathrm{HP} \gamma \mathrm{CD} /$ linalool-IC-NF could protect less linalool and possesses a higher stability constant than other $\mathrm{CD}$ types inhibiting the release of linalool, the total amount of released linalool was less than $\mathrm{HP} \beta C \mathrm{CD} /$ linalool-IC-NF and $\mathrm{M} \beta \mathrm{CD} /$ linalool-IC-NF.

The long-term release experiments were performed for $\mathrm{HP} \beta \mathrm{CD} /$ linalool-IC-NF, M $\beta C D /$ linalool-IC-NF, and $\mathrm{HP} \gamma \mathrm{CD} /$ linalool-IC-NF at RT and $18 \%$ RH for 50 days. The results are shown in Fig. $5 \mathrm{a}-\mathrm{c}$. $\mathrm{HP} \beta \mathrm{CD} /$ linalool-IC-NF, M $\beta \mathrm{CD} /$ linalool-IC-NF, and $\mathrm{HP} \gamma \mathrm{CD} /$ linaloolIC-NF could preserve $\sim 6.5 \%, \sim 10.5 \%$, and $\sim 6.0 \%$ at the end of 25 days, whereas $\sim 5.5 \%, \sim 10.0 \%$, and $\sim 6.0 \%$ of linalool was preserved at the end of 50 days, respectively. Based on the initial amounts in each sample, these amounts correspond to $\sim 68 \%$, $\sim 91 \%$, and $\sim 69 \%$ for 25 days and $\sim 60 \%, \sim 86 \%$, and $\sim 69 \%$ for 50 days, respectively. Owing to the high thermal stability of linalool in $\mathrm{M} \beta \mathrm{CD} /$ linalool-IC-NF, $\sim 86 \%$ of linalool was preserved in $\mathrm{M} \beta \mathrm{CD} /$ linalool-IC-NF at the end of 50 days. In the case of $\mathrm{HP} \beta \mathrm{CD} /$ linalool-IC-NF and $\mathrm{HP} \gamma \mathrm{CD} /$ linalool-IC-NF, the preservation of linalool was in the range of $60-70 \%$ after 50 days, which was less than the $\mathrm{M} \beta C D /$ linalool-IC-NF. Similar with the short-term release results, $\mathrm{HP} \beta \mathrm{CD} /$ linalool-IC-NF sample released the most linalool because of its lower thermal stability when compared to other two samples. In short, $\mathrm{M} \beta C \mathrm{C} /$ /inalool-IC-NF would be a better choice for long-term release of linalool, when compared to $\mathrm{HP} \beta \mathrm{CD} /$ linalool-IC-NF and $\mathrm{HP} \gamma \mathrm{CD} /$ linalool-IC-NF. In our previous studies, significant amounts of vanillin, geraniol, and allyl isothiocyanate were lost from PVA nanofibers without CD-IC during electrospinning or storage, even after one day of electrospinning (Aytac et al., 2014; Kayaci \& Uyar, 2012; Kayaci et al., 2014). However, linalool was preserved to a great extent in CD/linalool-IC-NFs even after 50 days of storage. Furthermore, we also recorded ${ }^{1} \mathrm{H}$ NMR spectra of $\mathrm{CD} /$ linalool-IC-NFs after incubating at RT for 25 days, in order to determine if there is oxidation in the samples (Fig. S3). Since there was no change in the ${ }^{1} \mathrm{H}$ NMR spectra of the samples, it was concluded that there was no sign of oxidationrelated loss in the samples after 25 days, so, the loss of linalool at this time is due to the evaporation.

The modified CDs are known to be less hygroscopic than native CDs (Uekama \& Otagiri, 1986; Yoshida, Arima, Uekama, \& Pitha, 1988). Here, CD/linalool-IC-NFs were kept at $80 \pm 2 \% \mathrm{RH}$ at RT, and we have observed that nanofibrous webs lost their fiber morphology and dissolved in a short time, due to very high humidity levels. So, CD/linalool-IC-NFs were exposed to $60 \pm 2 \% \mathrm{RH}$ at RT for up to $24 \mathrm{~h}$ and the amount of linalool for each sample was determined by TGA. Fig. S4 shows the TGA graphs of HP $\beta C D /$ linalool-IC-NF, $\mathrm{M} \beta \mathrm{CD} /$ linalool-IC-NF and $\mathrm{HP} \gamma \mathrm{CD} /$ linalool-IC-NF after exposing them to $60 \pm 2 \% \mathrm{RH}$ at RT for $6 \mathrm{~h}$ and $24 \mathrm{~h}$. The calculations for the remaining weight\% of linalool in each sample were based on the theoretical amount of linalool used for the preparation of solutions before electrospinning. The amounts of linalool in $\mathrm{HP} \beta C \mathrm{CD} /$ linalool-IC-NF, $\mathrm{M} \beta \mathrm{CD} /$ linalool-IC-NF and $\mathrm{HP} \gamma \mathrm{CD} /$ linalool-IC-NF at the end of $6 \mathrm{~h}$ at $60 \pm 2 \% \mathrm{RH}$ at RT were calculated as $8.86 \%, 11.20 \%$, and $8.34 \%$, respectively. So, HP $\beta C D /$ linalool-IC-NF, $\mathrm{M} \beta \mathrm{CD} /$ linalool-IC-NF and $\mathrm{HP} \gamma \mathrm{CD} /$ linalool-IC-NF preserved $93 \%, 97 \%$, and $96 \%$ of linalool, compared to the initial amount of linalool present in each sample. After keeping samples at $60 \pm 2 \% \mathrm{RH}$ at $\mathrm{RT}$ for $24 \mathrm{~h}$, the amount of linalool retained in $\mathrm{HP} \beta \mathrm{CD} /$ linalool-IC-NF, M $\beta \mathrm{CD} /$ linalool-IC-NF and $\mathrm{HP} \gamma \mathrm{CD} /$ linaloolIC-NF was determined as $7.93 \%, 10.22 \%$, and $6.95 \%$, respectively, and this corresponds to $83 \%, 89 \%$, and $80 \%$ of initial amount of linalool, respectively. $\mathrm{M} \beta \mathrm{CD} /$ linalool-IC-NF released the least amount of linalool after exposure to $60 \pm 2 \% \mathrm{RH}$ at RT, in parallel with the long term release experiments, owing to its higher thermal stability. These results agreed well with the long term release studies in which $\mathrm{M} \beta \mathrm{CD} /$ linalool-IC-NF could preserve more linalool than $\mathrm{HP} \beta \mathrm{CD} /$ linalool-IC-NF and $\mathrm{HP} \gamma \mathrm{CD} /$ linalool-IC-NF.

\subsection{Antibacterial activity}

The terpene constituents present in essential oils disrupt the bacterial membrane of bacteria and therefore essential oils exhibit antibacterial activity (Delaquis, Stanich, Girard, \& Mazza, 2002). The antibacterial activity of $\mathrm{HP} \beta \mathrm{CD} /$ linalool-IC-NF, M $\beta C D /$ linaloolIC-NF, and $\mathrm{HP} \gamma \mathrm{CD} /$ linalool-IC-NF webs against $E$. coli and $S$. aureus was tested by using the viable cell-counting method (Fig. 6). As

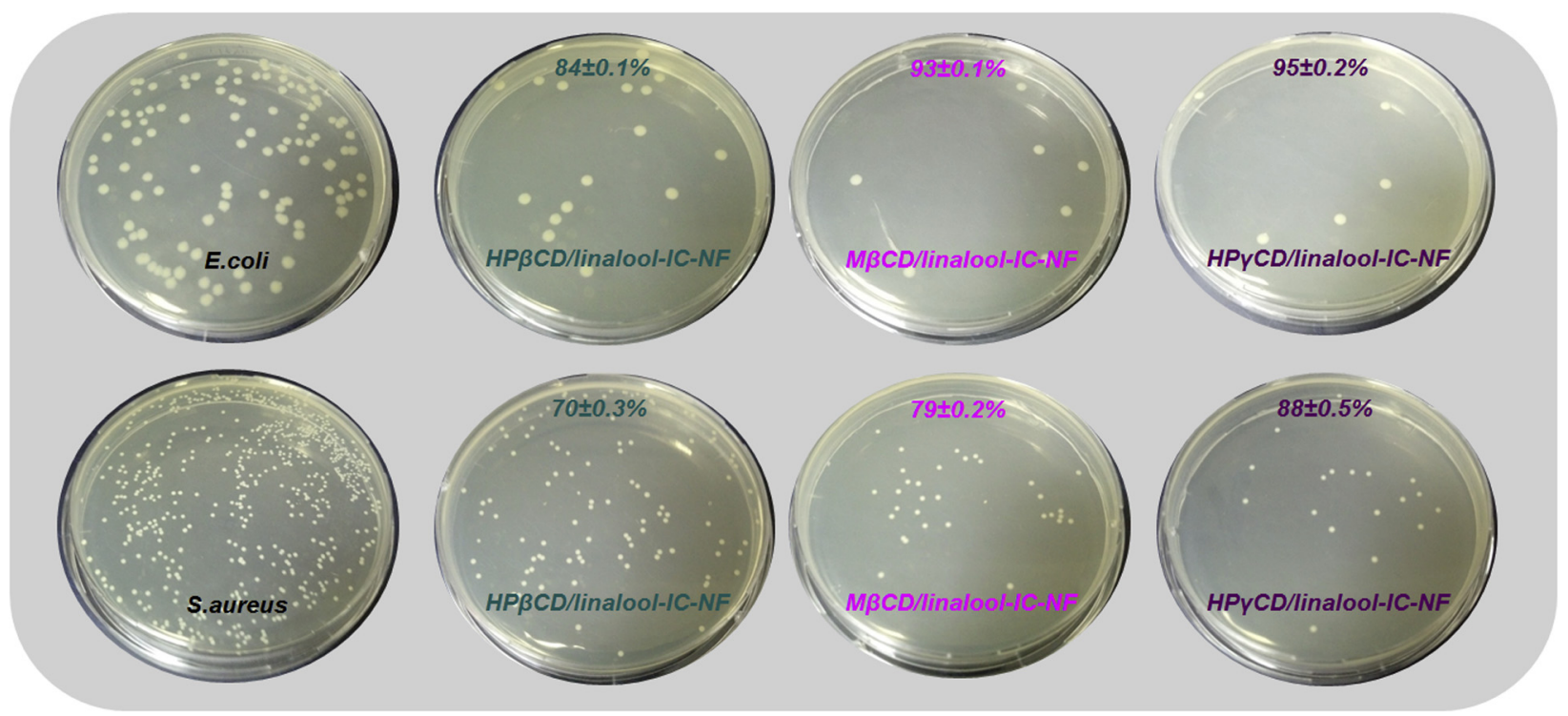

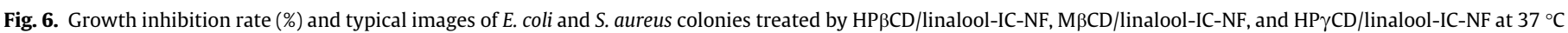
$(n=3)$. The error bars in the figure represent the standard deviations (SD). 
shown in the plates, $\mathrm{CD} /$ linalool-IC-NF samples had strong antibacterial activity against both model bacteria. The antibacterial activity of $\mathrm{HP} \beta \mathrm{CD} /$ linalool-IC-NF, M $\beta \mathrm{CD} /$ linalool-IC-NF, and $\mathrm{HP} \gamma \mathrm{CD} /$ linalool-IC-NF was $84 \pm 0.1 \%, 93 \pm 0.1 \%$ and $95 \pm 0.2 \%$ against E. coli, and $70 \pm 0.3 \%, 79 \pm 0.2 \%$, and $88 \pm 0.5 \%$ against $S$. aureus, respectively. Although the preserved amount of linalool was the least in $\mathrm{HP} \gamma \mathrm{CD} /$ linalool-IC-NF according to the NMR and TGA results, $\mathrm{HP} \gamma \mathrm{CD} /$ linalool-IC-NF has shown higher antibacterial efficiency than the $\mathrm{HP} \beta C \mathrm{CD} /$ linalool-IC-NF and $\mathrm{M} \beta \mathrm{CD} /$ linalool-IC-NF. This is possibly because of the higher solubility of $\mathrm{HP} \gamma \mathrm{CD} /$ linalool-IC than the HP $\beta C D /$ linalool-IC and $\mathrm{M} \beta \mathrm{CD} /$ linalool-IC, as confirmed by the phase solubility studies. This result correlated with the literature where essential oils have shown much higher antibacterial efficiency when complexed with modified CDs (i.e. $\mathrm{HP} \beta C \mathrm{CD})$, compared to native $\mathrm{CDs}(\alpha-\mathrm{CD}, \beta-\mathrm{CD})$, due to the greater enhancement with regards to water solubility of essential oils (Liang, Yuan, Vriesekoop, \& Lv, 2012). In short, CD/linalool-IC-NFs are effective antibacterial materials against model Gram-negative and Gram-positive bacteria.

\section{Conclusion}

Free-standing nanofibers were produced from non-polymeric systems of cyclodextrin/linalool-inclusion complexes (CD/ linalool-ICs) via electrospinning. High amount of linalool (45$89 \%$ ) was preserved in $\mathrm{CD} /$ linalool-IC-NFs owing to cyclodextrin complexation. Short-term temperature release $\left(3 \mathrm{~h}\right.$ at $37^{\circ} \mathrm{C}$, $50{ }^{\circ} \mathrm{C}$, and $75^{\circ} \mathrm{C}$ ), long term open air release (50 days, at RT), and humidity dependent release $(60 \pm 2 \% \mathrm{RH}$ at $\mathrm{RT})$ tests were carried out for $\mathrm{CD} /$ linalool-IC-NFs. M $\beta C D$ /linalool-IC-NF released less linalool compared to $\mathrm{HP} \beta \mathrm{CD} /$ linalool-IC-NF in short-term temperature release and long-term open air release tests, due to its higher thermal stability and stability constant. CD/linalool-IC-NFs were shown to have quite high antibacterial activity against model Gramnegative (E. coli) and Gram-positive (S. aureus) bacteria. CD/ linalool-IC-NFs are shown to dissolve completely in water within two seconds. In brief, high preservation of linalool along with antibacterial activity and slow release were achieved by the electrospinning of $\mathrm{CD} /$ linalool-IC nanofibrous webs, which may be used as fast-dissolving supplement material in food and pharmaceutical products.

\section{Funding}

This work was supported by The Scientific and Technological Research Council of Turkey (TUBITAK)-Turkey (Project \# 213M185).

\section{Acknowledgement}

The Scientific and Technological Research Council of Turkey (TUBITAK)-Turkey (Project \# 213M185) is acknowledged for the financial support of this study. We would like to thank Dr. Asli Celebioglu for her continuous help for the electrospinning of cyclodextrin nanofibers. Z. Aytac, Z. I. Yildiz and F. KayaciSenirmak thank to TUBITAK-BIDEB; and Z. Aytac and Z. I. Yildiz also thank to TUBITAK (project no. 213M185) for the PhD scholarship. T.U thanks to The Turkish Academy of Sciences - Outstanding Young Scientists Award Program (TUBA-GEBIP)-Turkey for partial support.

\section{Appendix A. Supplementary data}

Supplementary data associated with this article can be found, in the online version, at http://dx.doi.org/10.1016/j.foodchem.2017. 03.113.

\section{References}

Aprotosoaie, A. C., Hăncianu, M., Costache, I. I., \& Miron, A. (2014). Linalool: A review on a key odorant molecule with valuable biological properties. Flavour and Fragrance Journal, 29(4), 193-219.

Aytac, Z., Dogan, S. Y., Tekinay, T., \& Uyar, T. (2014). Release and antibacterial activity of allyl isothiocyanate/ $\beta$-cyclodextrin complex encapsulated in electrospun nanofibers. Colloids and Surfaces B: Biointerfaces, 120, 125-131.

Aytac, Z., Kusku, S. I., Durgun, E., \& Uyar, T. (2016a). Encapsulation of gallic acid/cyclodextrin inclusion complex in electrospun polylactic acid nanofibers: Release behavior and antioxidant activity of gallic acid. Materials Science and Engineering: C, 63, 231-239.

Aytac, Z., Kusku, S. I., Durgun, E., \& Uyar, T. (2016b). Quercetin/ß-cyclodextrin inclusion complex embedded nanofibres: Slow release and high solubility. Food Chemistry, 197, 864-871.

Aytac, Z., Sen, H. S., Durgun, E., \& Uyar, T. (2015). Sulfisoxazole/cyclodextrin inclusion complex incorporated in electrospun hydroxypropyl cellulose nanofibers as drug delivery system. Colloids and Surfaces B: Biointerfaces, 128, 331-338.

Aytac, Z., \& Uyar, T. (2016). Antioxidant activity and photostability of $\alpha$-tocopherol $\beta$-cyclodextrin inclusion complex encapsulated electrospun polycaprolactone nanofibers. European Polymer Journal, 79, 140-149.

Aytac, Z., Yildiz, Z. I., Kayaci-Senirmak, F., San Keskin, N. O., Kusku, S. I., Durgun, E., ... Uyar, T. (2016). Fast-dissolving, prolonged release and antibacterial cyclodextrin/limonene-inclusion complex nanofibrous webs via polymer-free electrospinning. Journal of Agricultural and Food Chemistry. http://dx.doi.org/ 10.1021/acs.jafc.6b02632.

Aytac, Z., Yildiz, Z. I., Kayaci-Senirmak, F., San Keskin, N. O., Tekinay, T., \& Uyar, T (2016). Electrospinning of polymer-free cyclodextrin/geraniol-inclusion complex nanofibers: Enhanced shelf-life of geraniol with antibacterial and antioxidant properties. RSC Advances, 6(52), 46089-46099.

Barhate, R. S., \& Ramakrishna, S. (2007). Nanofibrous filtering media: Filtration problems and solutions from tiny materials. Journal of Membrane Science, 296(1), 1-8.

Bhushani, J. A., \& Anandharamakrishnan, C. (2014). Electrospinning and electrospraying techniques: Potential food based applications. Trends in Food Science E' Technology, 38(1), 21-33.

Bonetti, P., de Moraes, F. F., Zanin, G. M., \& de Cássia Bergamasco, R. (2016). Thermal behavior study and decomposition kinetics of linalool/ $\beta$-cyclodextrin inclusion complex. Polymer Bulletin, 73(1), 279-291.

Celebioglu, A., Kayaci-Senirmak, F., Ipek, S., Durgun, E., \& Uyar, T. (2016). Polymerfree nanofibers from vanillin/cyclodextrin inclusion complexes: High thermal stability, enhanced solubility and antioxidant property. Food E Function, 7, 3141-3153.

Celebioglu, A., Umu, O. C. O., Tekinay, T., \& Uyar, T. (2014). Antibacterial electrospun nanofibers from triclosan/cyclodextrins inclusion complexes. Colloids and Surfaces B: Biointerfaces, 116, 612-619.

Celebioglu, A., \& Uyar, T. (2010). Cyclodextrin nanofibers by electrospinning. Chemical Communications, 46(37), 6903-6905.

Celebioglu, A., \& Uyar, T. (2011). Electrospinning of polymer-free nanofibers from cyclodextrin inclusion complexes. Langmuir, 27(10), 6218-6226.

Celebioglu, A., \& Uyar, T. (2012). Electrospinning of nanofibers from non-polymeric systems: Polymer-free nanofibers from cyclodextrin derivatives. Nanoscale, 4, 621-631.

Ciobanu, A., Mallard, I., Landy, D., Brabie, G., Nistor, D., \& Fourmentin, S. (2012). Inclusion interactions of cyclodextrins and crosslinked cyclodextrin polymers with linalool and camphor in Lavandula angustifolia essential oil. Carbohydrate Polymers, 87(3), 1963-1970.

Del Valle, E. M. M. (2004). Cyclodextrins and their uses: A Review. Process Biochemistry, 39(9), 1033-1046.

Delaquis, P. J., Stanich, K., Girard, B., \& Mazza, G. (2002). Antimicrobial activity of individual and mixed fractions of dill, cilantro, coriander and eucalyptus essential oils. International Journal of Food Microbiology, 74(1), 101-109.

Góra, A., Sahay, R., Thavasi, V., \& Ramakrishna, S. (2011). Melt-electrospun fibers for advances in biomedical engineering, clean energy, filtration, and separation. Polymer Reviews, 51(3), 265-287.

Hedges, A. R. (1998). Industrial applications of cyclodextrins. Chemical Reviews, 98 (5), 2035-2044.

Higuchi, T., \& Connors, A. K. (1965). Phase-solubility techniques. Advances in Analytical Chemistry and Instrumentation, 4, 117-212.

Hu, C. Y., Chen, M., \& Wang, Z. W. (2012). Release of thymol, cinnamaldehyde and vanillin from soy protein isolate films into olive oil. Packaging Technology and Science, 25(2), 97-106.

Kadam, V. B., Bamane, G. S., \& Raut, G. S. (2014). Research Article Solubility Enhancement of Nebivolol Hydrochloride using $\beta-C D$ Complexation Technique. International Journal of Current Pharmaceutical Sciences, 1(1), 6-12.

Kayaci, F., Sen, H. S., Durgun, E., \& Uyar, T. (2014). Functional electrospun polymeric nanofibers incorporating geraniol-cyclodextrin inclusion complexes: High thermal stability and enhanced durability of geraniol. Food Research International, 62, 424-431.

Kayaci, F., \& Uyar, T. (2012). Encapsulation of vanillin/cyclodextrin inclusion complex in electrospun polyvinyl alcohol (PVA) nanowebs: Prolonged shelf-life and high temperature stability of vanillin. Food Chemistry, 133, 641-649.

Kriegel, C., Arrechi, A., Kit, K., McClements, D. J., \& Weiss, J. (2008). Fabrication, functionalization, and application of electrospun biopolymer nanofibers. Critical Reviews in Food Science and Nutrition, 48(8), 775-797. 
Liang, H., Yuan, Q., Vriesekoop, F., \& Lv, F. (2012). Effects of cyclodextrins on the antimicrobial activity of plant-derived essential oil compounds. Food Chemistry, 135, 1020-1027.

Mendes, A. C., Stephansen, K., \& Chronakis, I. S. (2016). Electrospinning of food proteins and polysaccharides. Food Hydrocolloids. http://dx.doi.org/10.1016 j.foodhyd.2016.10.022 (in press).

Noruzi, M. (2016). Electrospun nanofibres in agriculture and the food industry: A review. Journal of the Science of Food and Agriculture, 96(14), 4663-4678.

Numanoglu, U., Sen, T., Tarimci, N., Kartal, M., Koo, O. M., \& Onyuksel, H. (2007). Use of cyclodextrins as a cosmetic delivery system for fragrance materials: Linalool and benzyl acetate. AAPS PharmSciTech, 8(4), 34-42.

Sill, T. J., \& von Recum, H. A. (2008). Electrospinning: Applications in drug delivery and tissue engineering. Biomaterials, 29(13), 1989-2006.

Szejtli, J. (1998). Introduction and General Overview of Cyclodextrin Chemistry. Chemical Reviews, 98(97), 1743-1753.

Uekama, K., \& Otagiri, M. (1986). Cyclodextrins in drug carrier systems. Critical Reviews in Therapeutic Drug Carrier Systems, 3(1), 1-40.

Uyar, T., \& Kny, E. (2017). Electrospun materials for tissue engineering and biomedica applications: Research, design and commercialization. Elsevier, Woodhead Publishing Series in Biomaterials. June 2017 (ISBN: 9780081010228).
Uyar, T., Hacaloglu, J., \& Besenbacher, F. (2009). Electrospun polystyrene fibers containing high temperature stable volatile fragrance/flavor facilitated by cyclodextrin inclusion complexes. Reactive and Functional Polymers, 69(3), $145-150$.

Uyar, T. Nur, Y, Hacaloglu, J. \& Besenbacher, F. (2009). Electrospinning of functional poly(methyl methacrylate) nanofibers containing cyclodextrinmenthol inclusion complexes. Nanotechnology, 20(12), 125703.

Uyar, T., Nur, Y., Hacaloglu, J., \& Besenbacher, F. (2011). Electrospun polyethylene oxide (PEO) nanofibers containing cyclodextrin inclusion complex. Journal of Nanoscience and Nanotechnology, 11, 3949-3958.

Wendorff, J. H., Agarwal, S., \& Greiner, A. (2012). Electrospinning: Materials, processing and applications. Weinheim: John Wiley \& Sons Publishing.

Yoshida, A., Arima, H., Uekama, K., \& Pitha, J. (1988). Pharmaceutical evaluation of hydroxyalkyl ethers of $\beta$-cyclodextrins. International Journal of Pharmaceutics, 46 (3), 217-222.

Yu, D. G., Shen, X. X., Branford-White, C., White, K., Zhu, L. M., \& Bligh, S. A. (2009). Oral fast-dissolving drug delivery membranes prepared from electrospun polyvinylpyrrolidone ultrafine fibers. Nanotechnology, 20(5), 055104. 